\title{
Promotive and preventive programs about basic life support in Medan Barat district
}

\author{
Bastian Lubis $^{1 *}$, Putri Amelia ${ }^{1}$, Ali Nafiah Nasution ${ }^{1}$, Melati Silvanni Nasution ${ }^{1}$, Rizky Adriansyah ${ }^{1}$ \\ ${ }^{1}$ Faculty of Medicine, Universitas Sumatera Utara, Medan, Indonesia \\ *Email: bastian.lubis@usu.ac.id
}

\begin{abstract}
Cardiac arrest remains a prominent public health problem and cause of death globally. Despite there is no national data of Indonesia available currently, around 350,000 people in the United States and Canada experienced an arrest every year, and half of them were dead. The community knowledge and awareness about basic life support, particularly among mothers, is still low. Therefore, they cannot contribute effectively in providing first-aid to reduce the mortality. To improve this situation, we need an education and training program about basic life support for the PKK mothers and Posyandu cadres in West Medan to reduce the mortality rate of cardiac arrest in Indonesia. The activity was conducted in several stages, from basic data collection, lectures, basic life support practical training, evaluation and guidebooks handover. It was attended by 26 people, 15 women $(57.7 \%)$ and 11 men $(42.3 \%)$, with a mean age of 39 years old. No significant change was found in the level of knowledge and behavior before and after the activity (Z-score: 0,$001 ; p=1,000)$.
\end{abstract}

Keywords: Basic life support, Cardiac arrest, PKK, Posyandu

\begin{abstract}
Abstrak
Henti jantung masih menjadi permasalahan kesehatan masyarakat dan penyebab utama kematian di dunia. Meskipun data nasional di Indonesia belum ada, sekitar 350.000 orang mengalami henti jantung setiap tahunnya di Amerika Serikat dan Kanada dan setengah dari kasus ini berakhir dengan kematian. Pengetahuan dan kesadaran masyarakat, terutama kaum ibu, dalam pemberian bantuan hidup dasar (basic life support) masih kurang sehingga belum mampu berkontribusi dalam menekan angka kematian yang tinggi ini. Oleh karena itu, suatu program edukasi dan pembinaan mengenai bantuan hidup dasar diperlukan bagi ibu-ibu PKK dan kader Posyandu di Kecamatan Medan Barat untuk menurunkan mortalitas akibat henti jantung di Indonesia. Kegiatan dilaksanakan dalam beberapa tahapan mulai dari pengumpulan data dasar, edukasi berupa ceramah, pelatihan bantuan hidup dasar, evaluasi keberhasilan, hingga penyerahan buku panduan dan poster. Kegiatan dihadiri 26 orang dewasa, 15 perempuan (57.7\%) dan 11 laki-laki (42.3\%) dengan rerata usia 39 tahun. Tidak ditemukan perubahan signifikan dari tingkat pengetahuan dan perilaku sebelum dan sesudah kegiatan (Z-score: 0,$001 ; p=1,000$ ).
\end{abstract}

Kata kunci: Bantuan hidup dasar, Henti jantung, PKK, Posyandu

\section{PENDAhuluan}

Henti jantung merupakan masalah kesehatan masyarakat yang penting dan penyebab utama kematian di dunia. Sebagian besar korban henti jantung adalah orang dewasa (Travers, et al., 2010). Kondisi ini menyebabkan kematian mendadak ketika sistem kelistrikan jantung tidak berfungsi dan menghasilkan irama yang tidak normal (WHO, 2011). Kejadian henti jantung sulit diperkirakan karena berkembang dengan cepat setelah gejala muncul. Jika tidak ditangani dengan segera, henti jantung akan menjadi gawat darurat medis. Pemberian pertolongan sedini mungkin dapat menyelamatkan nyawa penderita (AHA, 2014). 
Kejadian henti jantung di dunia terus meningkat. Pasien yang dirawat di rumah sakit, khususnya di ruang gawat darurat, mempunyai risiko yang tinggi. Di Amerika Serikat dan Kanada, 350.000 orang mengalami henti jantung setiap tahunnya dan setengahnya meninggal dalam perawatan (Bon, C.A., 2017). Lima dari 1000 pasien yang dirawat di rumah sakit Australia diperkirakan mengalami henti jantung dan sebagian besar pasien tidak mampu bertahan hidup hingga keluar rumah sakit. Sekitar $81 \%$ kasus disebabkan oleh penyakit jantung koroner, dan memiliki penyakit jantung lainnya juga meningkatkan risiko kejadian henti jantung (Berg, et al., 2010).

Indonesia belum memiliki data statistik yang jelas mengenai angka kejadian henti jantung di rumah sakit setiap tahunnya (AHA, 2015). Berdasarkan studi pendahuluan di IGD RSUD dr. Iskak Tulungagung, rerata kunjungan IGD pada Januari hingga Desember 2013 adalah 32.140 pasien, dengan rerata harian mencapai 89 pasien. Pasien dengan status gawat darurat sebanyak 18.176 pasien dan kejadian henti jantung pada periode 1-7 maret 2015 sebanyak 13 pasien. Pasien ROSC sebanyak 6 pasien (46\%) dan 7 pasien (54\%) meninggal dunia.

Berdasarkan American Heart Association (AHA) 2015, tindakan untuk dapat mempertahankan kehidupan pada henti jantung adalah penerapan chain of survival yaitu pertolongan pertama saat terjadi henti jantung hingga perawatan setelahnya. Basic Life Support (BLS) merupakan pertolongan dasar pertama dan Advanced Cardiovascular Life Support (ACLS) merupakan bantuan hidup lanjut pada pasien henti jantung (American Red Cross, 2015).

Mitra pada pengabdian masyarakat ini adalah ibu-ibu PKK dan kader Posyandu di Kelurahan Kesawan, Kecamatan Medan Barat. Wilayah ini berada sekitar 6 km dari Fakultas Kedokteran Universitas Sumatera Utara (FK USU). Masyarakat pada kelurahan tersebut berjumlah sekitar 98.203 jiwa.

Berdasarkan visi dan misi FK USU dalam memberikan pelayanan kesehatan terbaik pada masyarakat dan program kerja Puskesmas Kecamatan Medan Barat juga menitik beratkan pada peningkatan kualitas dan pemberdayaan masyarakat. Dikarenakan henti jantung masih menjadi masalah kesehatan utama baik di negara maju dan berkembang, suatu program promotif dan preventif mengenai bantuan hidup dasar sangat diperlukan bagi masyarakat di Kecamatan Medan Barat sebagai upaya menurunkan angka kematian henti jantung di Indonesia.

\section{METODE PELAKSANAAN}

Metode yang dilakukan pada kegiatan ini adalah dengan cara menilai data dan tingkat pengetahuan dasar para ibu-ibu PKK dan kader Posyandu mengenai bantuan hidup dasar menggunakan kuesioner pre-test. Selanjutnya, penyuluhan dan pelatihan mengenai henti jantung dan bantuan hidup dasar diberikan kepada peserta. Hasil dari kegiatan kemudian dinilai dengan mengisi kembali kuesioner pengetahuan bantuan hidup dasar dan kuesioner perilaku. Akhirnya, aktivitas ditutup dengan penyerahan buku panduan, poster, dan fasilitasi PKK dan Posyandu dalam deteksi dini, penanganan awal dan pencegahan henti jantung.

\section{HASIL DAN PEMBAHASAN}

Sebelum pelaksanaan kegiatan penyuluhan dan pelatihan dilakukan survei tingkat pengetahuan peserta mengenai bantuan hidup dasar untuk mengukur keberhasilan program ini. Sejumlah 26 
Bastian, et al Promotive and preventive programs about basic life support in Medan Barat district

orang peserta dewasa, terdiri dari 15 orang perempuan (57.7\%) dan 11 orang laki-laki (42.3\%), mendapatkan penyuluhan mengenai bantuan hidup dasar. Rerata usia adalah 39 tahun (rentang usia 18 - 74 tahun). Pekerjaan terbanyak adalah aparatur sipil negara sebanyak 10 orang (38.5 \%), ibu rumah tangga 7 orang $(26.9 \%)$, wiraswasta 6 orang $(23.1 \%)$, dan mahasiswa 3 orang (11.5\%). Berdasarkan tingkat pendidikan terakhir, sebagian besar peserta berpendidikan terakhir lulusan SMA sebanyak 19 orang (73.1\%), lulusan perguruan tinggi 5 orang (19.2\%), dan lulusan SMP 2 orang $(7.7 \%)$.

Dari segi pengetahuan dan informasi mengenai bantuan hidup dasar, sebanyak 17 orang (65\%) pernah mendengar ataupun mengetahui informasi mengenai bantuan hidup dasar. Sembilan orang (35\%) tidak pernah mengetahui atau mendapat informasi mengenai bantuan hidup dasar.

Pada uji bivariat, berdasarkan hasil pre-test, tingkat pengetahuan peserta terbanyak sebelum diberikan penyuluhan termasuk dalam kategori cukup, yaitu 14 orang (54\%) dan pada kategori baik 12 orang (46\%). Hal ini menunjukkan bahwa tingkat pengetahuan peserta mengenai bantuan hidup dasar masih dalam kategori cukup. Sementara itu, setelah dilakukan post-test, hasil yang sama didapatkan, yaitu tingkat pengetahuan terbanyak setelah penyuluhan adalah kategori cukup 14 orang (54\%), dan pada kategori 12 orang (46\%). Hasil analisis menunjukkan skor Z sebesar 0,001 dengan nilai $p$ value sebesar 1,000 $(p>\alpha)$, sehingga diputuskan tidak ada perbedaan pada tingkat pengetahuan peserta mengenai bantuan hidup dasar sebelum dan sesudah diberikan penyuluhan (Tabel 3.1).

\begin{tabular}{ccccccc}
\hline Tingkat & \multicolumn{2}{c}{ Pre - test } & \multicolumn{2}{c}{ Post - test } & \multirow{2}{*}{ Skor Z } & \multirow{2}{*}{ Nilai p } \\
\cline { 2 - 5 } Pengetahuan & $\mathrm{N}$ & $\%$ & $\mathrm{~N}$ & $\%$ & & \multirow{2}{*}{0,000} \\
\hline Baik & 12 & 46 & 12 & 46 & 0,001 & \\
Cukup & 14 & 54 & 14 & 54 & & \\
Kurang & 0 & 0 & 0 & 0 & & \\
Total & 26 & 100 & 29 & 100 & & \\
\hline
\end{tabular}

Tabel 3.1. Perbedaan tingkat pengetahuan peserta sebelum dan sesudah pemberian penyuluhan 
Bastian, et al Promotive and preventive programs about basic life support in Medan Barat district

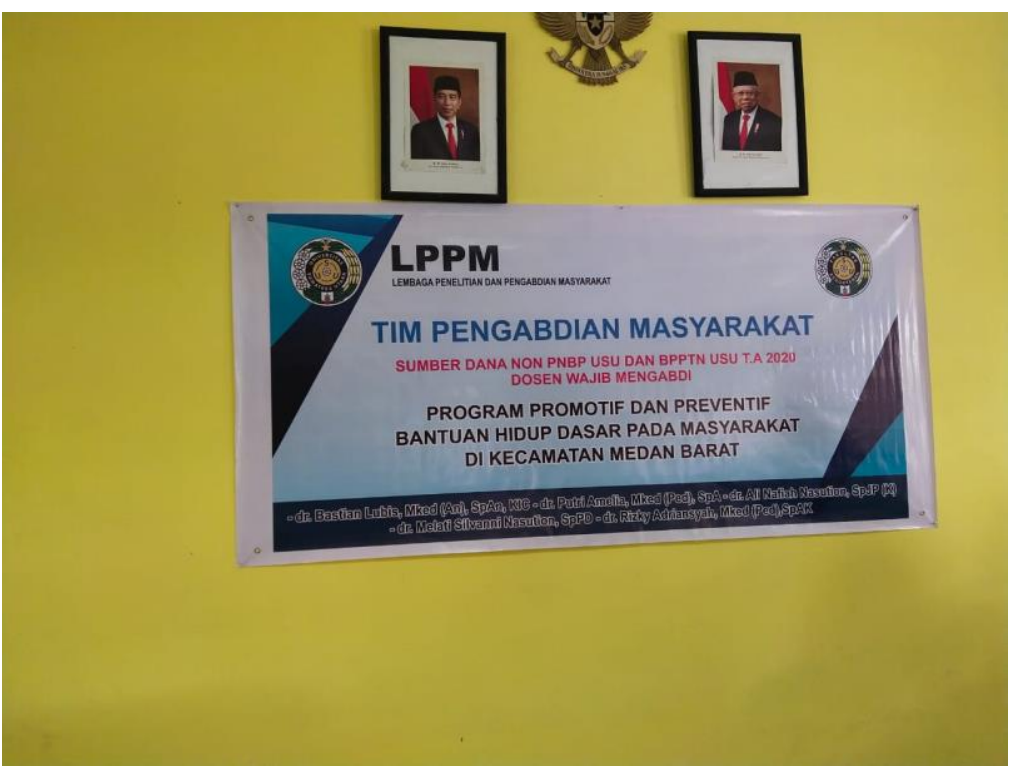

Gambar 3.1. Penyuluhan bantuan hidup dasar

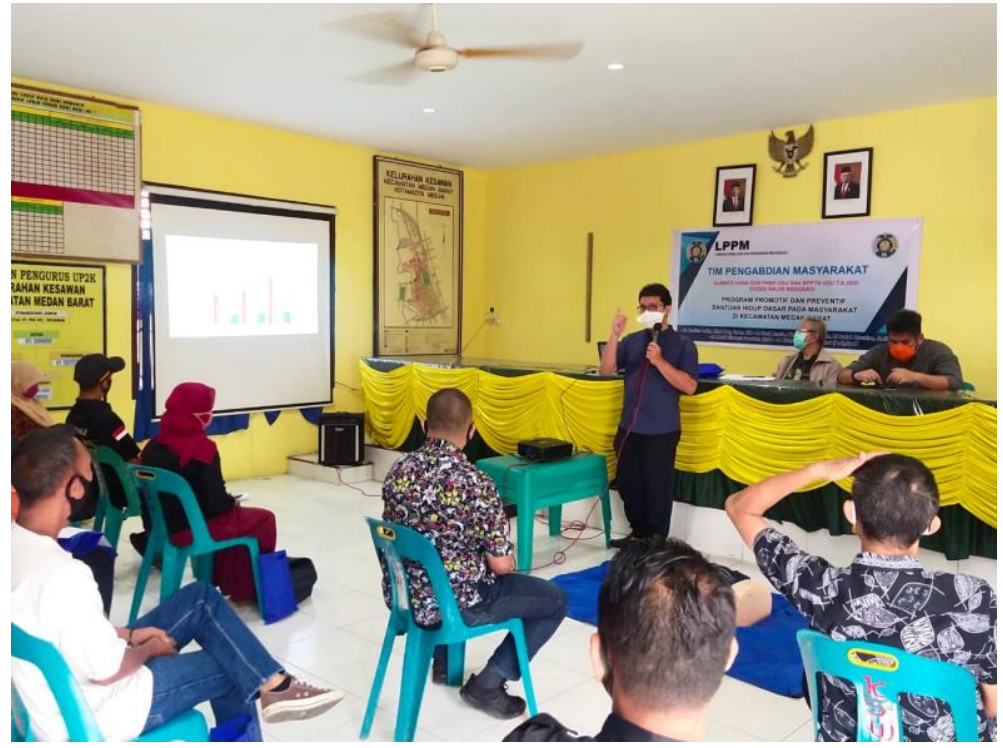

Gambar 3.2. Pemberian materi bantuan hidup dasar 


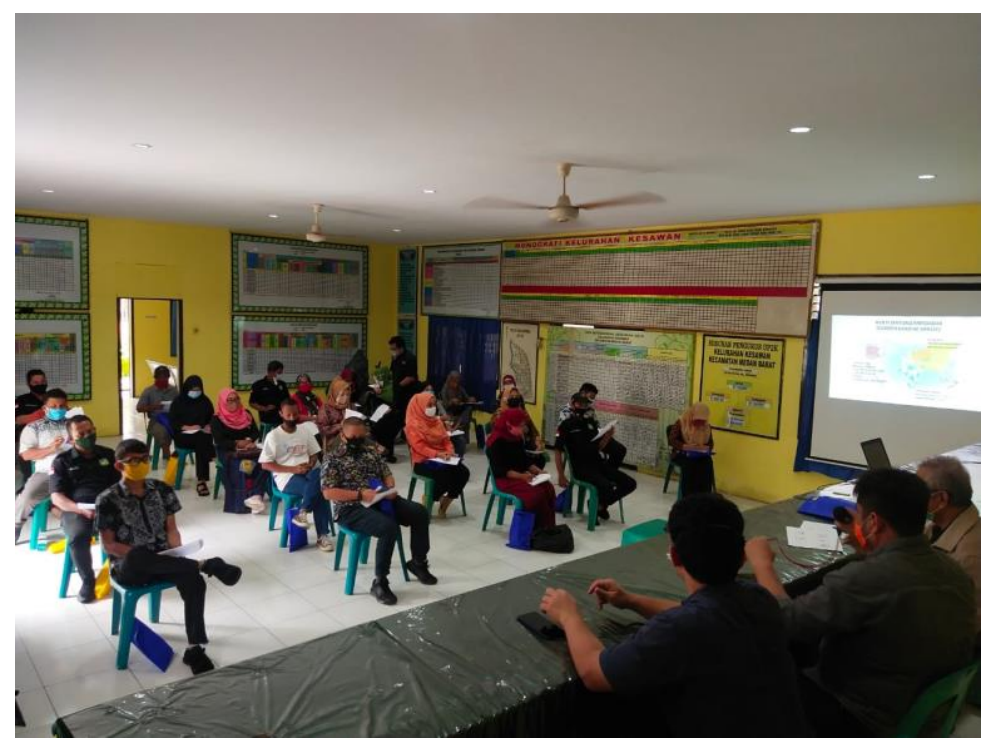

Gambar 3.3. Pelaksanaan post-test setelah penyuluhan

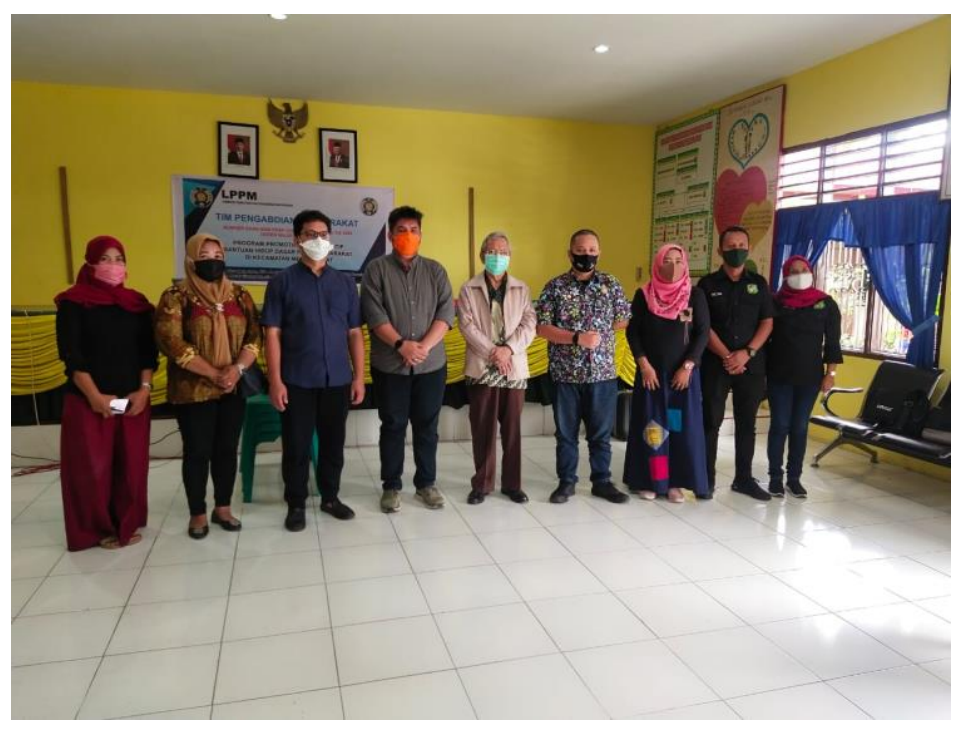

Gambar 3.4. Foto bersama pembicara dan peserta penyuluhan

\section{KESIMPULAN DAN SARAN}

\subsection{Kesimpulan}

Karakteristik dari 26 orang peserta kegiatan pengabdian masyarakat disusun berdasarkan tingkat pendidikan terakhir dan jenis kelamin. Sebagian besar peserta dengan pendidikan terakhir lulusan SMU sebanyak 19 orang $(73.1 \%)$. Kegiatan dihadiri oleh 15 orang perempuan $(57,7 \%)$ dan 11 orang laki-laki (42,3\%). Tidak ada perbedaan tingkat pengetahuan peserta sebelum dan sesudah 
penyuluhan mengenai bantuan hidup dasar berada pada kategori cukup sejumlah 14 orang (54\%) dan kategori baik sejumlah 12 orang (46\%).

\subsection{Saran}

Tim penggerak PKK Kelurahan Kesawan dapat terus mengembangkan ilmu yang telah didapat dan melaksanakan penyuluhan bagi anggota tim penggerak PKK kelurahan lain di Kecamatan Medan Barat.

\section{UCAPAN TERIMAKASIH}

Ucapan terima kasih kami sampaikan kepada Universitas Sumatera Utara, Wakil Rektor III yang membawahi kegiatan pengabdian masyarakat ini, Dekan Fakultas Kedokteran Universitas Universitas Utara, Dinas Kesehatan Kota Medan, dan mitra kami yaitu PKK Kecamatan Medan Barat, Kota Medan yang telah membantu kami dalam keberhasilan penyelenggaraan pengabdian masyarakat ini.

\section{DAFTAR PUSTAKA}

American Heart Association (2010) 'Basic Life Support: 2010 American Heart Association Guidelines for Cardiopulmonary Resuscitation and Emergency Cardiovascular Care', Circulation, 122; S685-S705.

American Heart Association (2014) 'About cardiac arrest', [Internet]. [cited 25 November 2020]. Available from: http://www.heart.org/HEARTORG/Conditions/More/CardiacArrest/About-CardiacArrest_UCM_307905_Article.jsp

American Heart Association (2015) 'AHA guideline update for CPR and ECC', Circulation, 132. American Red Cross (2015) 'Basic life support for healthcare providers', [Internet], [cited 25 November 2020]. Available from: https://www.redcross.org/content/dam/redcross/trainingservices/licensed-training-provider/BLS-FactSheet-2017.10.20.pdf

Bon, C.A (2017) 'Cardiopulmonary Resuscitation (CPR)', [Internet], [diperbarui 6 Februari 2017]. Available from: https://emedicine.medscape.com/article/1344081-overview\#a1

Berg, R.A., et al (2015) 'Part 5: Basic life support for healthcare providers', Adult American Red Cross.

Travers, A.H., et al (2010) 'Part 4: CPR Overview: 2010 American Heart Association Guidelines for Cardiopulmonary Resuscitation and Emergency Cardiovascular Care, Circulation, 122; S676-S684.

World Health Organization (2011) 'Global atlas on cardiovascular disease prevention and control', WHO, 164p. ISBN 978924156437. 